\title{
DE PIEL A PIEL: \\ EL EROTISMO COMO ESCRITURA EN LA NUEVA NARRATIVA FEMENINA DE CHILE
}

\author{
POR \\ Juan Armando Epple \\ Universidad de Oregon
}

En marcado contraste con la tradición narrativa femenina anterior a la dictadura(Marta Brunet, María Luisa Bombal, Elisa Serrano, Chela Reyes, Mercedes Valdivieso) donde la expresión del deseo de la mujer se mediatizaba en diversas estrategias de enmascaramientos simbólicos, transferencias y sublimaciones, se subordinaba a las temáticas de rebeldía social, o se expresaba en interdicción conflictiva, no resuelta, con los modelos discursivos protocolos de lectura masculinos, en la escritura creativa reciente, aquella surgida paradójicamente en condiciones de severa censura política e ideológica, la sexualidad y el erotismo se privilegian como los gestos semánticos más dinámicos y transgrecores de las propuestas de identidad genérica y social de la mujer. La experiencia erótica, sobre todo, adquiere una validación protagónica, ya sea como territorio de exploración y afirmación de una subjetividad sometida a controles y prohibiciones, como des-automatización y transgresión de roles genéricos y sociales, como zona de comunicación alternativa, piel verbalizada, y en sus expresiones más logradas como relación creativa entre escenificación del deseo y liberación de la escritura.

Bataille destacaba que la impronta del erotismo como hecho cultural es la eclosión radical e interiorizada que produce entre la prohibición y la libertad, el acatamiento a las normas y su transgresión. Para el autor "el conocimiento del erotismo, o de la religión, requiere una experiencia personal, igual y contradictoria, del interdicto y de la transgresión" (Bataille 53).

Esuna epifanía sensorial que hace presentey a la vez deroga los supuestos convencionales de la sexualidad, las reglas sociales y morales, inventando — de ahí su carácter lúdico— una personalidad amatoria cuyo poder de atracción se funda en la originalidad.

\section{SeXUALidAd y EROTISMO}

El acto sexual es la satisfacción natural del instinto, en tanto el erotismo (arte de amar) es la expresión cultural de las fantasías del deseo.

Si bien la demarcación entre pornografía y erotismo tiene zonas imprecisas, la pornografía se limita a la exhibición morosa de la actividad fisiológica, en una gratificación visual tendiente a excitar al espectador o lector. Es una representación que recorta y magnifica las anatomías recurrentes del placer, estimulando fantasías compensatorias de 
poder o sumisión, pero neutralizando el haz de sentimientos que debe convocar el juego erótico. De ahí que la ficción sexual del happening pornográfico resulte predecible y finalmente monótono: todas las escenas terminan pareciéndose.

A este reduccionismo narrativo y su despersonalización se refiere Susan Sontag en un conocido ensayo:

The universe proposed by the pornographic imagination is a total universe. It has the power to ingest and metamorphose and translate all concerns that are fed into it, reducing everything into the negotiable currency of the erotic imperative. All action is conceived of as a set of sexual exchanges (66).

El erotismo, en cambio, canaliza y transforma el apetito corporal en fabulaciones de ser: el cuerpo se personaliza como deseo en una búsqueda de correspondencias con el deseo del otro. Es energía sexual trasmutada en cultivo (cultura) de la sensualidad y en representación que proyecta y modela imaginariamente la propia interioridad en el otro ser. Como afirma Bataille: "El erotismo es uno de los aspectos de la vida interior del ser humano. Busca sin cesar afuera un objeto de deseo. Pero ese objeto responde a la interioridad del deseo. La elección de un objeto responde siempre a los gustos personales [...]" (53). Es esta virtualidad creadora lo que lo separa del dominio de la naturaleza y lo inscribe en los territorios de la cultura y del arte. Y han sido justamente los escritores los que han destacado esa correspondencia secreta entre el impulso erótico y el imperio de la imaginación. Para Cristina Peri Rossi, por ejemplo, el erotismo es la diversificada, y siempre cambiante, fantasía de corporización de los deseos:

En la imaginación (que inventa relaciones, símbolos, analogías, que exalta o que denigra), un cuerpo se transforma en objeto de deseo, destacándose, sobresaliendo entre los demás, como imantado, como iluminado por las luces y las sombras de la pasión (manía). Lo imaginario, que se construye como fabulación y representación, es decir, como símbolo y metáfora, intenta nombrar lo innombrable (el cuerpo del deseo) y transferir sus emociones al lenguaje, al poema, al cuadro, al cine (46).

Son conocidos los ensayos que le ha dedicado Octavio Paz a la cultura erótica de distintas civilizaciones y a su relación con la literatura. Paz sitúa el erotismo en el plano de las representaciones culturales: sexualidad que trasciende la función reproductora para erigirse gestualidad lúdica de los deseos. Una de sus propuestas más sugerentes, en este sentido, es la que vincula el erotismo a la poesía como rituales de la imaginación (10).

La tendencia crítica conocida como "Nuevo feminismo francés", de notoria influencia en el discurso crítico y la escritura latinoamericana a partir de los setenta, postuló como supuestos básicos la existencia de una sexualidad femenina diferenciada, de una erótica femenina, y de un lenguaje que debería expresar y re-inscribir el ethos femenino/feminista en la esfera pública de la cultura: una politización de la sexualidad.

A diferencia de la centralidad y discontinuidad de la sexualidad masculina, objetivada en la posesión sexual de la mujer, la sexualidad femenina es continua, múltiple, distendida en toda la geografía corporal y abierta a las sensaciones de la reciprocidad (Alberoni 224, 
Rubin Suleiman 13). Luce Irigaray destaca: "El sexo de la mujer está en todo su cuerpo [...] la geografía de su placer es mucho más diversificada, múltiple en sus diferencias, compleja, sutil, de lo que se ha imaginado [...] dentro de un imaginario que está demasiado centrado en lo único y lo mismo" (28).

Para Luce Irigaray, Hélène Cixous y Monique Wittig el reconocimiento de la especificidad del erotismo femenino conlleva un necesario reconocimiento y revaloración de la especificidad de su relación con el lenguaje. La descripción del cuerpo y el deseo femenino genera potencialmente una nueva poética expresiva, una escritura de desplazamientos, rupturas y transgresiones que al romper con las convenciones de la lógica lineal, la cadena sintáctica, la homogeneidad discursiva y la representación realista es capaz de canalizar una política centrada en la mujer.

Recuperar el cuerpo históricamente colonizado y reprimido, escribir desde y con los deseos, es un gesto de autoconocimiento y apertura que reformula radicalmente las relaciones simbólicas entre placer y poder, sexualidad y escritura, resituando protagónicamente el historial marginado de la mujer en una cultura en proceso de cambios (Gálvez-Carlisle 1994, 50).

\section{EROTISMO Y PODER}

Una lectura somera de la literatura erótica femenina publicada recientemente en el Cono Sur de América Latina hace presente una marcada correlación simbólica entre representación del deseo erótico y rearticulación de las relaciones políticas de poder. Este proceso se enmarca, a mi juicio, en una tendencia que engloba a la mayor parte de la producción literaria narrativa escrita durante y en las postrimerías de las dictaduras militares. Así como la producción narrativa más destacada, tanto de hombres como de mujeres, se replegó a los espacios privados de la casa o el círculo de amistades, a la memoria personal fracturada, a la búsqueda traumática del padre o del maestro (una reiteración obsesiva del tópico de la orfandad como metáfora de la búsqueda de la seguridad institucional), en un sueño siempre diferido de recomposición de tejidos sociales válidos, la literatura erótica femenina se repliega inicialmente a los territorios privados del deseo. Pero no lo hace ni desde una postura restrictivamente hedonista (aunque el hedonismo es uno de los elementos constitutivos de la poética erótica) ni desde una concepción esencialista del feminismo como oposición radical hombre/mujer. Es un erotismo que explora y libera las fantasías de una subjetividad que se sabe sometida a una red de restricciones institucionales (desde la familia, la educación, la sociabilidad política, hasta el Estado), para distenderse luego al espacio público, interpelando sus convenciones y códigos culturales y re-inscribiendo esos deseos como textualidad socializadora. La erótica se convierte así en lo que era primordialmente: un acto de socialización del deseo, una inventiva y un saber cuya realización radica en su posibilidad de ser compartidos. No es extraño entonces que el despertar erótico se inicie, en la mayoría de los textos, como una reacción a situaciones extremas de las protagonistas, como la soledad, el silencio, la marginalidad social, e incluso los estigmas de la edad biológica. El cuerpo erótico que se va pre-figurando en estos imaginarios no es sólo autentificación del placer individual, sino que es un cuerpo historizado, un "archivo de traumas" como lo llama la escritora argentina 
María Luisa Lerer, que se entreteje en las fisuras de los entramados sociales para proponerle otros territorios de sentidos:

Lo transgresor erótico, sobre lo cual en este momento escribimos, son sensaciones que las mujeres hemos tenido durante muchos años silenciadas. Sin duda la erótica, y la literatura erótica, tiene que ver con abandonar los disfraces sociales y las caretas y todo aquello que nos ponemos para no decir exactamente lo que nuestros fantasmas amorosos, nuestras fantasías, nuestros entretejidos de deseos van diciendo. [...] Creo que las mujeres empezamos a escribir en la medida en que nos encontramos con nuestro cuerpo. Nuestro cuerpo, archivo de traumas, desde donde vamos sacando afuera, vamos pariendo aquellas fantasías eróticas, fantasías que tienen que ver con nuestros quereres, nuestros saberes, con aquello que deseamos y pocas veces podemos conversarlo, hablarlo o hacerlo saber a quien convive con nosotros (68).

\section{Los SENTIDOS POLÍTICOS DE EROS}

En lo que sigue nos centraremos en la demarcación y análisis de lo que consideramos temas relevantes de la nueva escritura erótica de mujeres en Chile.

En una sociedad profundamente conservadora, clasista y racista como la chilena, la celebración de la sexualidad de la mujer, de la comunicación erótica entre sujetos de distintos estratos socioculturales, la escenificación franca de los tabúes que fiscalizan las conductas, perfilan poéticas transgresoras que interpelan tanto el uso institucionalizado del cuerpo impuesto por la cultura judeo-cristiana como el disciplinamiento normativo del orden nacional ejecutado por la dictadura y luego avalado por el "consenso" democrático, que no hizo sino reajustar a un sistema tradicional de representaciones simbólicas los roles genéricos, sociales y políticos de los sujetos masculino y femenino.

En la lucha por la recuperación de los derechos civiles y por la redemocratización de la sociedad chilena el movimiento de mujeres tuvo un rol destacado, pero una vez desmovilizado y con sus propuestas más innovadoras coptadas por las negociaciones consensuales de la política, su presencia como agente social y cultural en el "nuevo" discurso de la nación volvió a ocupar un plano secundario. Es esta derogación brusca de expectativas, esta experiencia de seducción social y abandono, este sentirse de pronto fuera de juego, lo que moviliza ahora un imaginario que reinvindica las grafías sensoriales del cuerpo como energía vital postergada, como memoria indigente, como discursividad acallada (Trevizán 57).

La preocupación por resemantizar el cuerpo de la mujer, en este reajuste aparentemente democratizador, implica proponerlo tanto como espacio de supresiones y represiones como zona a re-escribir, como posiblidad de gestar un discurso social alternativo.

Refiriéndose a la dimensión política que adquiere la representación del cuerpo, Raquel Olea señala:

Formular el gesto escritural en su política de propuesta que se desplaza de la materialidad corporal a la productividad de una textualidad señalada por las marcas de lo biográficosocial, advierte de un posicionamiento que asume la marca sexual como signo relevante de la constitución del texto literario. La escritura del cuerpo tiene en el Chile de la 
dictadura el signo de la respuesta y resistencia al castigo, a la tortura y a la violencia de Estado desatada sobre los cuerpos (por cierto, no sólo de mujeres).

Simbolizar el cuerpo como espacio de confrontaciones que interroga la historia, como memoria del dominio étnico y genérico, pasa por buscar en los intersticios del lenguaje que lo nombra las articulaciones de poderes que lo han significado. Si lo femenino puede ser metáfora que ilumina "todo resquicio marginado y privado del poder central" (Eltit), constituir un habla que emerja de la propia materialidad corporal de la mujer puede contribuir con el trazo de su historia a la creación de un nuevo lenguaje como voluntad de avalar resignificaciones del cuerpo. Actitud del todo política como gestión de posicionamientos constituyentes de nuevo poder (Olea 105).

Uno de los gestos perturbadores en relación a las convenciones tradicionales de la sexualidad femenina es el autoerotismo, pues desautoriza o difiere la acción masculina en la generación de placer. Hay varios relatos que se centran en esa zona tabú de la experiencia masturbatoria, donde la mujer explora su cuerpo y elabora fantasías ya sea frente a un espejo, una ventana o en ensoñaciones asociadas a imágenes acuáticas o selváticas. En la mayoría de los casos se trata de mujeres casadas o con una pareja estable, lo que resignifica el sentido del acto masturbatorio a la vez como protesta y reclamo de independencia.

En los textos eróticos de Pía Barros la mujer que se masturba, en un impulso siempre convocado por esa desterritorialización espacio-temporal que produce lluvia, configura con su deseo, y a veces corporiza fantásticamente, ese objeto pasional verdadero (el idealizado complemento natural) que le ha sido negado ya sea por las convenciones sociales o por la domesticación de su sexualidad. En su relato "Deshabitados frente a una ventana", de la colección $A$ horcajadas (Barros 1992) un hombre y una mujer, desconocidos entre sí, le relatan a un psiquiatra sus respectivas experiencias masturbatorias, sin saber que se han poseído el uno al otro imaginariamente. En "Olor a madera y a silencio" una mujer escapa de su rutina matrimonial entregándose a fantasías eróticas con un desconocido que la acaricia y la posee en sus momentos de aburrimiento. Poco a poco, a la vez que le va inventando al hombre detalles físicos y un espacio salvaje opuesto a las demarcaciones del cuerpo social urbano, esos sueños eróticos que la satisfacen plenamente le van dejando huellas reconocibles en la piel. Pero en un momento la ensoñación erótica escapa a su control mental y la arrastra a un encuentro que borra los límites entre la lengua de la naturaleza y la saliva de la comunión erótica, en una suerte de regreso a un estadio primigenio del mundo, de rango panteísta:

los zapatos de un hombre sobre el pasto [...], la lengua y los dientes arañando sus pezones la lanzaron de lleno a un mar embravecido y la urgencia de su piel en el deseo a un infierno Ilameante que le secó la boca y le borroneó su propia silueta de voyeur espiando el juego [...] por la piel le reptó la mano y la mirada verde y entreabrió los muslos llamándolo, con un olor ancestral que desconocía en sí misma y la cabaña se volvió una grieta en la roca que le rasguñaba la espalda y el mar estaba allá, rugidor, lamiendo las pantorrillas que ella subió para quedar a horcajadas sobre el hombre vertical al que el mar parecía tratar de derribar con el oleaje y la espuma rugiendo sobre sus nalgas y las piernas entrecruzadas en la espalda a la que ella clavaba las uñas tratando de marcar, de dejar huella, y el hombre la embestía hasta nublarle los ojos y dejar un hilillo en la comisura de los labios [...] $(A$ horcajadas 28). 
El objeto de la pasión autoerótica se construye siempre como una figura intercambiable. Es como si la mujer asumiera la definición platónica de Demitrea, en El banquete: "el amor es lo que ama y no lo amado".

El primer libro de relatos de Andrea Maturana, (Des)encuentros (des)esperados (1992) describe una serie de episodios amatorios cuyo rasgo común es la fugacidad y precariedad de los contactos: despertar de los sentidos pasionales, roces, claudicaciones. Y son generalmente los hombres los que renuncian, por pacatería o por falta de imaginación, a asumir todas las consecuencias de la aventura erótica. Son ellos los que primero renuncian al juego transgresor para acatar las normas de las que pretendían liberarse. En uno de sus relatos más logrados, "Cita", una muchacha se deja seducir por las caricias de un desconocido que, en la aglomeración forzada de un carro del metro, la masturba con dedos hábiles y tiernos. Antes de bajar y desaparecer en las calles, el hombre le desliza en el bolsillo un papel con una dirección y una fecha. La muchacha acepta la cita como una oportunidad de perder la virginidad, "de salir de su tan defendida (y ridícula, pensó ahora), piel intacta. Cárcel intacta, se dijo". Ella acude al hotel, entra al cuarto indicado, y abandonándose a las incitaciones sensuales del ambiente, distiende un ritual autoerótico que se refracta dialogante en el espejo, ejercitando las caricias, la penetración, el desvirgamiento y el orgasmo que le ofrece al amante que ha inventado su memoria. Antes de abandonar el cuarto en que ha estado físicamente sola, escribe la palabra "gracias" en el mensaje de la cita y lo deja sobre el velador.

En el cuento "Galán con guitarra", de Sonia González, incluído en la colección Voces de eros (1997), una mujer que se prepara a abandonar su casa para iniciar una vida matrimonial que sabe signada por el orden y la rutina, ve en el autobús a un joven de aspecto vagabundo o bohemio, la antítesis de su futuro esposo, y lo ingresa a su mundo privado o su imaginación para fundar una relación de intimidad natural y lúdica que la acompañará de ahí en adelante en su trato con el marido, como un deseo alternativo.

La novela Los siete días de la señora K(1993), de Ana María del Río, relata el proceso de redescubrimiento de la energía erótica de una mujer sometida primero al ultraje de una violación infantil y luego a los actos de posesión rutinaria y egoísta del marido, quien la ha relegado a las funciones de servicio asignadas patriarcalmente a la mujer casada. La novela alcanzó un gran éxito de ventas, promocionándose en el mercado editorial por la osadía de su temática. Es muy posible que la popularidad de la novela se deba a las explícitas y detalladas descripciones de las escenas sexuales, especialmente la gozosa descripción de la masturbación de la mujer, algo inusitado en la narrativa chilena. Las propuestas de sentidos del texto van más allá de la simple escenificación vouyerista del deseo.

En primer lugar, la novela revierte la imagen tradicional de la casa como espacio consagrado a la normatividad reproductiva de la economía familiar y de la moral social. $\mathrm{Al}$ quedar sola por algunos días en su casa, la protagonista tiene la oportunidad de examinar su cuerpo frente al espejo y reconocerse por primera vez como sujeto con deseos y sabidurías pasionales reprimidas. La exploración del cuerpo ejerce un paulatino poder de seducción sobre el espacio, erotizándolo. La casa, posesionada ahora por una subjetividad en tensión, empieza a liberar sonidos soterrados, llamados, a abrir puertas y celosías hacia una realidad a la vez atemorizadora y gozosa. 
Hay un logrado paralelismo simbólico entre la lectura sensorial que la mujer va haciendo de su cuerpo y la derogación de las barreras físicas de la casa-cárcel. El moroso proceso autoerótico — del que sólo citamos su momento climático - se inscribe en el tradicional campo metafórico del mar:

Sus dedos volvieron a los labios mayores que se hallaban anhelantes. Comenzó a rodear con saliva, poco a poco, el óvalo ya humedecido donde se juntaban las dos carnosidades y fue posándolos suavísimamente sobre la lengua pequeña y ondulada de su clítoris, hundiéndose poco a poco los labios para sacarla al aire, haciéndose que éste se levantara de su quiste de silencio y plegamientos ciegos, renunciaciones a luz apagada y buscara, decidido, en la luz, los dedos.

Su músculo mojado, y medio por salirse de los labios se encontró en medio de las antenas de su placer.

El clítoris fue hinchándose y asomándose duro, carnoso y temblando como un ser nacido recién entre los dedos.

Tendida en la colcha de toda su vida, la señora $\mathrm{K}$. abrió y cerró las piernas moviendo los dedos desde los labios al clítoris, deteniéndose apenas en éste, pasándolo suavemente a llevar, con una aceleración que se semejaba una ola. La señora $\mathrm{K}$. sintió que su cuerpo entero era un nudo entrelazado, con una gota de paroxismo erguida en el nervio pequeño y potente del centro; las piernas se le trenzaban para aprisionar el placer y exprimirlo hasta la muerte; siguió en redondo con los dedos muy suaves, tentando los alrededores y posándose en el justo centro, casi sin tocarlo: su clítoris, crecido, saliente, clamaba florecido furiosamente (86-87).

Días después de esta autogratificación sexual, que parece generar correspondencias magnéticas con el espacio circundante, la protagonista ingresa a la casa a un joven cartero que le trae un telegrama del marido ausente y, tomando en todo momento la iniciativa, lo lleva a la sala principal y le prodiga una diestra y variada educación erótica (103-104).

Estableciendo un contraste de expectativas entre las posibles aventuras galantes del marido, sugeridas al comienzo de la novela, y lo que es capaz de vivir la esposa en la casa, el texto se apropia del modelo de la novela libertina pero lo defrauda con una resolución ambigua, que puede leerse como renuncia o reprensión irónica. Cuando aparece en su puerta un viejo cartero a dejarle el telegrama, a restituirla al orden de lo real, ella descubre asombrada que su experiencia erótica fue una fantasía materializada por el deseo, una transgresión imaginaria del estatuto convencional de la casa. La novela termina con una interrogante: la mujer anuda a su desnudez realizada la camisa del marido y espera. No sabemos si esa lectura del cuerpo modificará nuestros hábitos de lectura de lo femenino o lo recortará como otro fetiche pornográfico: si nuestra mirada será crítica o voyerista.

Si el autoerotismo convulsiona la relación de pareja y el orden contractual del hogar, hay otras aventuras eróticas que se divorcian del ámbito de lo privado-y de explicaciones psicologistas - para diseminar sus requisitorias en el orden público.

\section{Eros y Tanatos}

El vínculo metafórico entre cuerpo erótico y cuerpo social implica hacerse cargo de uno de los castigos más traumáticos que se ha ejercido sobre la mujer: la violación. Nunca 
se había abordado este tema con la amplitud y profundidad con que aparece en la narrativa reciente. La violación se lee no como una simple afrenta biológica a un cuerpo individual, sino como la consecuencia más degradante de la fuerza entendida como legitimación de poder. En Siete dias de la señora $K$ la violación que sufre la protagonista antes de la pubertad cancela abruptamente el desarrollo natural de su sexualidad. En la novela El daño (1997), de Andrea Maturana, la violación de la adolescente por su padre marca el cuerpo y la memoria de la protagonista con una llaga existencial que le impide verbalizar sus emociones y establecer vínculos con los demás: el estupro se prolonga como violación de su derecho al lenguaje. En los relatos "Mordaza", de Pía Barros, y "De brujas y mártires" (Frutos extraños) de Lucía Guerra, en la violación actual del cuerpo prisionero se inscribe la memoria de la conquista como un estigma: la imposición militar del poder del conquistador sobre el territorio ancestral significa también el usufructo brutal de la energía vital de la sexualidad y su domesticación ideológica.

Si la violación se ejerce en lugares despoblados o usurpados territorialmente (el campo, la noche, el sitio eriazo, la celda, etc.), el gesto de reconquista del poder sexual como derecho elemental, libertad sobre la propia naturaleza, se produce incursionando en esas mismas topografías, prefiguradas como territorios vigilados y en disputa, sitios de riesgo pero vulnerables a una erótica que intersecciona clases sociales, etnias, instituciones, etc. El ejercicio de la libertad erótica como precondición para recuperar las libertades genéricas y sociales implica confrontar así un espacio usurpado y mancillado por el dolor y la muerte. La confrontación radical entre erotismo y muerte es presentada en esta literatura con un despliegue temático inusual. Desde aquellos relatos de Voces de Eros, donde los desplazamientos vitalizadores del deseo erótico tienen un destino funesto ("Como si fueras" de Alejandra Basualto, "Gran señora y Rajadiablas" de Teresa Calderón, "En el parque" de Alejandra Costamagna, "Dúo" de Flavia Radrigán y "Más duro que mármol a mis quejas" de Ana María del Río) hasta los cuentos y novelas donde las pulsaciones de Eros verbalizan una dinámica de estrategias que invaden y subvierten territorios humanos signados tanto por la muerte física como por el conformismo funerario de las conciencias. Desde los textos que sueñan el retorno al mito andrógino, la utopía explicitada en Cierta femenina oscuridad (1996), de Eugenia Prado Bassi, y entretejida a nivel inconsciente en El daño, de Andrea Maturana, hasta los que historizan el deseo como recursos y discursos de resistencia.

En Muñeca brava (1993), de Lucía Guerra, una dictadura militar arquetípica se propone completar el proceso de disciplinamiento del cuerpo nacional con un proyecto de control y domesticación de la sexualidad. Para ello crea un centro de detención especial dedicado al estudio sociológico de la prostitución. El tema evoca con evidente ironía la festiva novela de Mario Vargas Llosa Pantaleón y las visitadoras, pero su entramado narrativo se articula como una parodia de la ideología positivista tan cara a los militares y del modelo de la novela naturalista. La resistencia política al sistema encuentra una alianza inesperada justamente en esta zona de marginalidad extrema de la sociedad, ese excedente fuera de control, a la vez deseado y censurado. Como destaca Lilianet Brintrup, la novela argumenta que la fiscalización extrema de la libertad sexual se correlaciona ideológicamente con la represión de toda disidencia discursiva (Brintrup 158). Las prostitutas subvierten el estatuto históricamente degradado del oficio (una de ellas describe retrospectivamente la historia cultural de la prostitución hasta sus orígenes sagrados), liberan en un acto de 
solidaridad emocional el poder del sexo y la seducción de su manipulación mercantil y lo reinvindican como "valor social". Pero esta politización de la fuerza sexual, o esta legitimación política de la "mujer pública", implica un proceso de transformación de la sexualidad en erotismo, y del erotismo en amor. La novela describe este proceso con lograda verosimilitud estética. Las relaciones eróticas entre las protagonistas y los jóvenes rebeldes revocan esa dicotomía ideológica entre sentimiento y razón, placer y compromiso militante. Es una comunión que precede secuencialmente al sacrificio de los personajes en la insurrección popular, resignificando así la alianza entre deseo y acción, y la intersección ominosa entre erotismo y muerte.

La llama erótica como experiencia límite que exorciza la inevitabilidad de la muerte es también el tópico del relato "Penitentes" de Pía Barros (Voces de Eros). Una mujer cuyo cuerpo presiente la erosión de una enfermedad terminal busca en la intimidad orgiástica con el amante y en la renovación de los deseos tras la "pequeña muerte" de que hablaban los griegos los conjuros creadores para aplazar la separación definitiva.

\section{El CUERPO COMO SEDUCCIÓN TEXTUAL}

En el hermoso relato "Dama en el jardín" de Carolina Rivas (Voces de Eros), una escritora acepta como secretaria a una joven taciturna y melancólica para que le vaya transcribiendo el dictado de una novela. Mientras trabajan, la escritora urde mentalmente un cuento en que la muchacha, luego de una experiencia sexual no deseada, es seducida y modelada eróticamente a través de las descripciones de su cuerpo que vienen en las cartas de un admirador anónimo. Una vez que ella se identifica con la imagen que esas cartas van haciendo de su cuerpo y sus deseos, al punto de vivirlas como volición, de poseerse a sí misma en la grafía que la nombra, la escritora le dicta el cuento basado en las cartas y mira el asombro de la muchacha al entender que había sido conquistada por la escritura y que esa topografía del deseo se fusionaría ahora con la realidad.

Este relato condensa ejemplarmente esa aspiración poética de convertir el texto en cuerpo erótico, en juego especular que proyecta los deseos, los hace intervenir creadoramente en las percepciones y voliciones adormecidas del sujeto interpelado, y los devuelve a la mirada convertidos en identidades diseminadas o pluralizadas y en propuestas movilizadoras de sentidos.

El tono menor del deseo (1991), de Pía Barros, se estructura a partir de este entramado especular. La narradora observa a una mujer que se mira en un espejo y la escribe proyectando su propia subjetividad en un espacio textual que se distiende cómplice y aleatorio. La mujer del espejo, a su vez, parece refractar la historia de dos mujeres que han sido socialmente signadas de acuerdo a las oposiciones binarias mujer buena mujer mala, espiritual carnal angélica/demoníaca, y que entrecruzan y modifican sus destinos gracias en parte a su intervención en la lucha política contra una dictadura. Una de ellas es Catalina, que ha aceptado las convenciones idealizadoras del "ángel del hogar" (la mujer como esposa, madre, enfermera), anulando su sexualidad, y que al quedar viuda debe enfrentarse abruptamente consigo misma. La otra es Melba, que una vez soñó con ser monja pero ha terminado siendo estigmatizada como la mujer mala, objeto de la pasión y el rencor masculino, y que ha buscado en diferentes relaciones un complemento erótico liberador 
idealizado en el personaje de El lobo estepario de Hermann Hesse. El resquebrajamiento de la historia social del país les permite modificar sus roles e intervenir en esas fracturas, erotizando en el caso de Catalina sus ideales solidarios, politizando en el caso de Elba sus dones eróticos. La mujer frente al espejo, estragada por el tiempo, busca la memoria de lo que pudo ser, descubriendo que existe una memoria corporal, una memoria-piel, y que esa memoria está hecha tanto de lo vivido como de los deseos diferidos. Romper el espejo es exorcizar y re-inscribir esta identidad, liberarla en la fluidez desestabilizadora de un texto pluralizado que la escribe. Y quien la escribe se está escribiendo a sí misma, es eco y protagonista de una memoria que existe sólo como grafía, que se corporiza en la virtualidad del texto.

Todas estas mujeres comparten una experiencia en que fueron obligadas a escindir sus identidades entre el juego erótico, que es creatividad, y la reglamentación social de la pasión. Por eso sus expectativas de realización humana se marcan como fracturas existenciales, $o$ se inscriben en la piel como recuerdos de una incompletud. Como juego de sustituciones entre lo que les ha sido dado vivir, y representar, y lo que no pudieron crear. La memoria de la mujer sin nombre que se mira al espejo es la de todas ellas:

El hombre lejano que la deseó, cerraba los párpados entreabriéndolos para mirarla, para hacerla descubrir en esa mirada cosas, trazos de ella misma que desconocía o que hubiera querido ser. Ella quiso soñar que él tenía una sed de besos en los párpados. Siempre la había enternecido un hombre mirándola. Percibía el desesperado afán de ver dentro de ella, de develarla, la obsesión de descifrar. Eso la hacía vulnerable y sentía una lástima agridulce que la llevaba a mentir para protegerlos, para que siguieran siendo un abismo temeroso que la dulcificaba y no pudieran transformarse en espadas o heridas. Los hombres siempre querían conocer las reglas del juego, cuando lo importante era jugar, la invención y violación de esas reglas a cada instante, la inutilidad de establecer reglas (1114).

El deseo es así ausencia, una promesa postergada de realización, pero que las refunda en la corporalidad imaginaria del texto.

Sin duda la propuesta estética más creativa y consistente en esta búsqueda de resignificaciones de la relación entre cuerpo textual femenino y cuerpo histórico, y entre deseo y escritura, es la de Diamela Eltit. Valorada como una de las voces más innovadoras de la narrativa latinoamericana reciente, sus novelas se caracterizan por entretejer y a la vez des-atar una densa trama de sentidos, alterando la lógica del relato para mostrar la relación problemática entre sujeto, referente histórico y discurso, obligando a reeducar nuestros códigos de lectura.

Vaca sagrada (1991) configura una poética de re-significación del cuerpo como territorio en que convergen y se neutralizan mutuamente identidades pre-asignadas (individual, social, cultural) y depósitos de experiencias y prácticas no verbalizadas o que sólo pueden exhibirse como huellas visuales. El cuerpo - la página de una escritura posible--aparece así como territorio vaciado de significaciones rectoras, de codificaciones culturales válidas, y poblado de esos signos residuales, de esos excesos, que quedaban fuera del recorte normativizador de las representaciones. Este proceso de transgredir modelos discursivos y literarios y des-narrar ficciones metaforiza la discontinuidad social e histórica 
de los discursos consagrados y propone enunciaciones en fricción, aleatorias o investidas de inquietantes permutaciones, aludiendo a la imposibilidad de categorizar con certeza experiencias y sujetos marginados o indóciles a las secuencias representativas del poder.

Huérfanos de Historia/historia, cuerpos en busca de identidades, estos sujetos habitan en un espacio de desamparo y en las concreciones extremas de sus pulsaciones vitales: el dolor y el placer. De ahí que sólo puedan ejercer presencia social potenciando sus gestos sensoriales y encarnándolos en los desajustados engranajes de una textualidad móvil, en ebullición o supura.

Sandra Lorenzano ha explicado con perspicacia el entramado textual de la novela:

En primer plano se teje una compleja trama de relaciones que explora los vínculos entre cuerpo y poder. Los cuerpos que funcionan como escenarios de goce, pero también de violencia y represión, son colocados en situaciones extremas. Extrema es también la búsqueda escritural, y es en este sentido que habría que considerar las diseminaciones sintácticas, semánticas y simbólicas de sus obras [...] Según la propuesta de Eltit, la sangre no será solo un tema dentro del hilo del relato, sino que ese "exceso" marcará uno de los capítulos centrales de la novela, "Los diez dias de Francisca Lombarda", en los que se busca que el ritmo de escritura siga el ritmo del sangrado femenino. Pero la sangre, que es el núcleo del deseo —en el cuerpo y la escritura — está también vinculada a la muerte y al dolor: "la sangre había perdido en mí cualquier rango que no fuera su irreversible conexión con la muerte" (44) (Lorenzano 125-126).

Los personajes reformulan sus borraduras existenciales en simula:iones de representación (si ustedes me reconocen como mentira deberán reconocer la falsedad de sus miradas homogeneizadoras), en la autoadjudicación de una subjetividad trasnsitoria o nómade, y en los excesos eróticos. Estos últimos corporizan la energía de lo prohibido y lo silenciado. Este deseo transgresor de ser, se re-somatiza en la novela como goce escritural: erotización del texto.

Vaca sagrada textualiza la disociación entre el deseo de liberación del cuerpo cultural femenino y la necesidad de pensarlo históricamente, en un tiempo en que hemos doblegado nuestra memoria y nuestras utopías a la erótica consumista, al hedonismo afásico del mercado. Sandra Garabano analiza la novela como escenificación de pluralidades discursivas, en un despliegue erotizado de versiones textuales que buscan ilusoriamente referentes escamoteados, interpelando desde sus carencias y supresiones esos discursos sociales conformistas, transadosy acreditadas desde "el desencanto y el vacío que deja la imposibilidad de construir utopías a través del lenguaje, y la inhabilidad de pensar históricamente" (Garabano 122-123).

Las formas del erotismo, en la nueva narrativa de mujeres, diseminan estrategias de escritura que libera los sentidos para proponer, en su juego seductor de lecturas, otras rearticulaciones posibles de lo humano. Otro modo de entender nuestras carencias y nuestras energías pasionales. Otro modo de lamer nuestras heridas históricas y convertirlas en saliva de palabras. Porque en principio - ese principio que suele descartarse con cierta liviandad-y esta es la raíz del juego, el arte de la seducción está en la lengua. 


\section{Obras CITADAS}

Alberoni, Francesco. El erotismo. Barcelona: Editorial Gedisa, 1994.

Aguirre, Mariano (ed.). Voces de Eros. Santiago: Mondadori, 1997.

Barros, Pía. El tono menor del deseo. Santiago: Editorial Cuarto Propio, 1991. A horcajadas Astride. Santiago: Editorial Asterión, 1992.

Brintrup, Lilianet. "Muñeca Brava: diálogo entre militares y prostitutas". Formaciones sociales e identidades culturales en América Latina. Ensayos en honor de Juan Armando Epple. Rosamel Benavides, ed. Valdivia: Ediciones Barba de Palo, 1997. 151-166.

Bataille, Georges. El erotismo. Barcelona: Tusquets, 1979.

Del Río, Ana María. Siete días de la señora K. Santiago: Editorial Planeta, 1993.

Eltit, Diamela. Vaca sagrada. Santiago: Editorial Planeta, 1991.

Gálvez-Carlisle, Gloria. “Desde 'La pasión de la Virgen' a Horcajadas: subjetividad, distopia y transgresión erótica”. Acta Literaria 19 (1994): 49-58.

Garabano, Sandra. "Vaca sagrada de Diamela Eltit: del cuerpo femenino al cuerpo de la historia”. Hispamérica 73 (1996): 121-127.

Guerra, Lucía. Frutos extraños. Caracas: Monte Ávila Latinoamericana, 1990. Muñeca brava. Caracas: Monte Ávila Latinoamericana, 1993.

Irigaray, Luce. Ce Sexe qui n'en est pas un. París: Eds. de Minuit, 1977.

Lerer, María Luisa. "Escritura y libertad". Mujeres y escritura. Mempo Giardinelli, ed. Buenos Aires: Editorial Puro Cuento, 1989. 68-69.

Lorenzano, Sandra. "Cuerpo y narrativa: explorando un territorio político". Formaciones sociales e identidades culturales en América Latina. Ensayos en honor de Juan Armando Epple. Rosamel Benavides, ed. Valdivia: Ediciones Barba de Palo, 1997. 111-130.

Maturana, Andrea. (Des)encuentros (des)esperados. Santiago: Editorial Los Andes, 1992. El daño. Santiago: Alfaguara, 1997.

Olea, Raquel. "La mujer ha salido al escenario. Suya es la palabra". Poesía chilena de los ochenta". Hispamérica 76/77 (1997): 101-112.

Paz, Octavio. La llama doble. Amor y erotismo. Barcelona: Seix Barral, 1993.

Peri Rossi, Cristina. Fantasías eróticas. Madrid: Ediciones Temas de Hoy, 1991.

Platón. El banquete. Madrid: Tecnos, 1998.

Prado Bassi, Eugenia. Cierta femenina oscuridad. Santiago: Editorial Cuarto Propio, 1996.

Sontag, Susan. "The Pornographic Imagination". Styles of Radical Will. Nueva York: Dell, 1970. 35-73.

Suleiman, Susan Rubin. "(Re) Writing the Body: The Politics and Poetics of Female Eroticism". The Female Body in Western Culture. Susan Rubin Suleiman, ed. Cambridge, MA/Londres: Harvard University Press, 1986. 7-29.

Trevizán, Liliana. Politica/sexualidad: nudos en la escritura de mujeres latinoamericanas. Lanham, MD: University Press of America, 1997. 